\title{
Herbivory by sucking mirid bugs can reduce nectar production in Asphodelus aestivus Brot.
}

\author{
Yael Samocha $\cdot$ Marcelo Sternberg
}

Received: 10 March 2009/Accepted: 14 April 2010/Published online: 29 April 2010

(C) The Author(s) 2010. This article is published with open access at Springerlink.com

\begin{abstract}
This experimental study focused on the effects of a mirid bug herbivore, Capsodes infuscatus on the flower nectar yield of a Mediterranean geophyte, Asphodelus aestivus. The effects of increasing densities of adult C. infuscatus bugs on A. aestivus, on the nectar volume and concentration were examined. Significant decreases were found in the number of flowers and nectar production as C. infuscatus densities increased. Analysis of covariance (ANCOVA) showed that nectar production was not affected by environmental variables (air temperature, relative air humidity and day-time) that were treated as covariates for the various bug herbivory intensities. Sugar concentration did not vary significantly among treatments, indicating that abiotic conditions were not responsible for differing nectar amounts. In light of A. aestivus's dependence on pollinator visits to produce seeds, we conclude that $C$. infuscatus could impair pollination success by reducing the amount of nectar in flowers. To the best of our knowledge, the present study is the first to show that insect herbivores do not necessarily have to remove segments from the flower in order to decrease nectar secretion.
\end{abstract}

Keywords Capsodes infuscatus - Geophyte . Leaf damage $\cdot$ Plant-insect interaction

Pollination success $\cdot$ Seed production

Handling Editor: Anna-Karin Borg-Karlson

Y. Samocha $\cdot$ M. Sternberg $(\bowtie)$

Department of Plant Sciences, Tel Aviv University,

69978 Tel Aviv, Israel

e-mail: Marcelos@tauex.tau.ac.il

\section{Introduction}

Nectar production in plants is affected by both biotic and abiotic factors. Abiotic factors play an important role in nectar production, as they affect its evaporation, condensation, and secretion, and its re-absorption by the plant (Corbet 1978). One of the most important biotic factors that affect nectar production is foraging by pollinators, which changes the standing yield of nectar (Corbet 1978; Pacini et al. 2003; Nicolson 2007). Whether this is done in the course of pollination or through simply "stealing" the nectar, it has a direct effect on flower nectar availability. Few studies have addressed the indirect effects of insect herbivore activity on flower nectar productivity. Indirect effect occurs when an herbivore causes changes in floral traits that may affect pollinator activity; for example, leaf damage may influence corolla diameter and thus reduce fruit set because of diminished pollinator preference or attraction (Mothershead and Marquis 2000). Potential indirect effects of herbivory on plant fitness, which accompany pollen-associated rewards, such as reduced pollen export, smaller pollen grains, and reduced numbers of staminate flowers or pollen grains, have been described previously (Quesada et al. 1995; Krupnick and Weis 1999; Lehtilä and Strauss 1999), but little is known about the effect of herbivory on nectar rewards. In the present study we examined whether an herbivore that does not consume nectar can affect nectar yield by feeding from leaves and inflorescence stalks. The studied insect herbivore was a mirid bug, Capsodes infuscatus, which is monophagous and feeds on leaves and inflorescences of Asphodelus aestivus Brot.

Asphodelus aestivus Brot. (synonyms A. microcarpus Salzn., A. ramosus L.) is a common Mediterranean geophyte belonging to the Liliaceae family (Feinbrun-Dothan 
and Danin 1998). Each paniculate inflorescence comprises tens to hundreds of flowers, and flowering starts at the base of each branch and proceeds towards the tip (Schuster et al. 1993). The flowers open synchronously in the morning and close in the evening of the same day, and on the following day the style withers completely, so that the stigma cannot receive any more pollen (Lifante 1996). The plant is selfcompatible, but insects are required in order to achieve a successful pollination because the stigma is located higher than the anthers (Schuster et al. 1993). Lifante (1996) found that $A$. aestivus nectar secretion rate was constant throughout the day, and that the amount of sugar content increased until the flower withered; however, the volume and concentration of the nectar changed in response to environmental conditions. Pollinators, of which Hymenoptera are the most frequent visitors, are attracted to the nectar as well as to the pollen (Lifante 1996). A. aestivus is characterized by septal ovarial nectary (Fahn 1990). The nectar is discharged from small holes in the ovary and stored in a cavity (sealed off by 6 stamens base, which surround the ovary); thereby, reducing evaporation (Sawidis et al. 2008).

Soon after the first rain, $C$. infuscatus nymphs emerge from the bases of dry A. aestivus leaves and/or previous year's dry inflorescence stalks, and feed by sucking on A. aestivus leaves, thereby causing leaf discoloration. Alternatively, if inflorescence stalks are developing, nymphs prefer them as a food source (Ayal 1994). C. infuscatus is characterized by piercing-sucking mouth parts (Alon 1985), and feeding by nymphs can suppress the development of the inflorescence (Ayal 1994). Plants that overcome the original feeding activity and develop inflorescences are exposed to damage to their buds, flowers and fruits by adult bugs (Ayal and Izhaki 1993). Previous studies have shown that this mirid bug can reduce reproductive success of A. aestivus by destroying up to $100 \%$ of their fruit production (Ayal and Izhaki 1993). In the present study we asked: Does mirid bug herbivory affect flower production and nectar secretion in A. aestivus? Nectar production is important for rewarding pollinators, and its reduction can decrease pollinators' visiting rates. Thus, considering the essential role of pollinators in achieving fruit production in A. aestivus, the effect of herbivores on nectar production may have an indirect negative impact on plant fitness.

\section{Materials and methods}

Study site and treatments

Forty mature tubers of A. aestivus were randomly collected in summer 2004 from a natural site in suburban Tel Aviv, Israel $\left(32^{\circ} 7^{\prime} \mathrm{N}, 34^{\circ} 48^{\prime} \mathrm{E}\right)$. Tubers were dug out with shovels and collected from clearly distinguished individual plants, separated by at least $2 \mathrm{~m}$. At this natural site, $C$. infuscatus had not been observed in the two previous winter seasons of tuber collection.

Individual A. aestivus tubers were then brought to Tel Aviv University Botanical Garden and transplanted into polystyrene containers containing peat soil. The tubers were transplanted to a nethouse in September 2004, just before the start of the rainy season. Following leaf emergence, the plants were irrigated regularly with a sprinkler system. The nethouse protected the plants from any contact with $C$. infuscatus or any other insect herbivores. Out of the 40 transplanted tubers, only 14 produced inflorescence stalks, with one to three inflorescences per plant. Following maturation of the inflorescence stalks and beginning of the blooming period, the herbivory treatments started. Treatments included different herbivory pressure on the inflorescence stalk covered with an organza fabric bag as follows: (a) stalks with five adult $C$. infuscatus; (b) stalks with ten adult $C$. infuscatus and (c) stalks with no $C$. infuscatus individuals served as controls. Each treatment was replicated seven times. Each inflorescence stalk was covered with its organza fabric bag from 1 day before the beginning of the herbivory experiment through the following four study days in February 2005. Numbers of flowers per inflorescence were counted daily, and the flowers were examined for nectar yield from midday till dusk, i.e., from 14:30 to 17:30 hs. Nectar volume was estimated with the aid of 10- and 1- $\mu$ l microcapillary tubes, and the exact time of the day was recorded. Sugar concentration in the nectar was also examined, as sucrose equivalent, with manual refractometers (Bellingham \& Stanley Ltd., Tunbridge Wells, UK), and the data were corrected against the "International Temperature Correction Table" (1936) for determining the sucrose percentage by mean of refractometer when the readings are made at a temperature other than $20^{\circ} \mathrm{C}$. Flowers from each treatment were taken randomly for nectar measurements, and nectar was assessed in three flowers per inflorescence, unless fewer flowers were present. In addition to these measurements, abiotic conditions, i.e., temperature and relative humidity, were recorded with a digital thermo-humidity meter. Table 1 present the numbers of studied flowers and plants, in addition to the mean temperature and humidity associated with all measurements in each treatment. Table 1 also shows equivalent abiotic conditions as well as similar measurements number for each treatment.

Data analysis

All data collected during the study period were merged and subjected to ANCOVA. Covariate factors were temperature, relative humidity and time of day. Nectar 
Table 1 C. infuscatus herbivory treatments and environmental variables measured during each experiment day

$R H$ relative humidity

\begin{tabular}{lcllll}
\hline Date & $\begin{array}{l}\text { Density treatment } \\
\text { (No of bugs per bag) }\end{array}$ & $\begin{array}{l}\text { No of examined } \\
\text { flowers }\end{array}$ & $\begin{array}{l}\text { No of examined } \\
\text { plants }\end{array}$ & $\begin{array}{l}\text { Mean } \\
\text { temp. }\left({ }^{\circ} \mathrm{C}\right)\end{array}$ & $\begin{array}{l}\text { Mean } \\
\text { RH }(\%)\end{array}$ \\
\hline 14.2 .2005 & 0 & 6 & 2 & 15.4 & 33.0 \\
& 5 & 9 & 3 & 15.9 & 32.7 \\
15.2 .2005 & 10 & 4 & 2 & 15.6 & 32.7 \\
& 0 & 9 & 3 & 18.6 & 32.7 \\
16.2 .2005 & 5 & 9 & 3 & 19.1 & 32.3 \\
& 10 & 8 & 4 & 18.5 & 32.7 \\
& 5 & 11 & 4 & 21.4 & 37.3 \\
17.2 .2005 & 10 & 12 & 5 & 22.2 & 36.1 \\
& 0 & 10 & 5 & 21.9 & 36.0 \\
& 5 & 9 & 3 & 22.4 & 38.2 \\
Total & 10 & 9 & 3 & 23.0 & 36.9 \\
& 0 & 12 & 5 & 22.9 & 37.1 \\
& 5 & 35 & & & \\
\hline
\end{tabular}

volume and sugar concentrations were tested in each treatment. The nectar volume data were $\log (\mathrm{x})$ transformed and the sugar concentration data, expressed as sucrose percentages, were arcsin transformed, following a normal distribution test. Numbers of flowers per treatment were subjected to ANOVA. The differences were subjected to post-hoc examination with the Tukey-Kramer HSD test, by means of the JMP 5.01 software (SAS Institute Inc. Cary, NC).

\section{Results}

Significant $(P<0.01)$ differences were noted between the average numbers of flowers per inflorescence in the several herbivory density treatments (Fig. 1). Fewer buds per inflorescence started anthesis as the mirid bug sucking pressure on stalks increased. Total nectar production per flower ranged from 0 to $5.64 \mu \mathrm{l}$, and it too diminished as herbivory pressure on the stalks increased (Fig. 2). Differences between control and bug exposure treatments were highly significant $(P<0.001)$, with less nectar in flowers that were exposed to higher numbers of $C$. infuscatus trapped in the bag. In several measurements there was no nectar at all. It is important to emphasize that at no point in the observations were $C$. infuscatus insects seen feeding on nectar directly from flowers. The environmental covariates (time of day, temperature and relative humidity) did not elicit significant effects on either nectar production or sugar concentration, indicating that differences among treatments in nectar traits were not due to environmental conditions. The sugar concentration in nectar was similar in all treatments (Fig. 3).

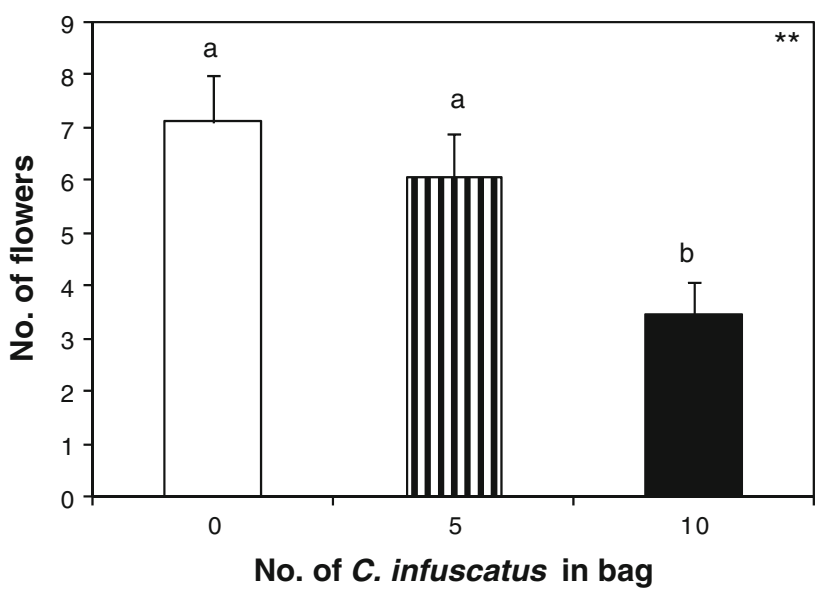

Fig. 1 Number of blooming flowers per inflorescence in the various infestation density treatments. Different letters indicate significant differences among treatments according to Tukey's HSD test. ** Indicates $P<0.01$

\section{Discussion}

Our results suggest that the mirid bug's activity of sucking on inflorescence stalks leads to a reduction in the total number of blooming flowers. Similar results were noted in desert populations of A. aestivus, where the mirid bug's feeding included flower buds and flowers (Ayal and Izhaki 1993): damage to the buds would most likely cause a reduction in the total number of flowers. Production of fewer flowers because of herbivory is not rare and has been observed on other plants also (Karban and Strauss 1993; Quesada et al. 1995; Strauss et al. 1996; Juenger and Berelson 1997; Lehtilä and Strauss 1997; Mothershead and Marquis 2000). This activity may exert an important 


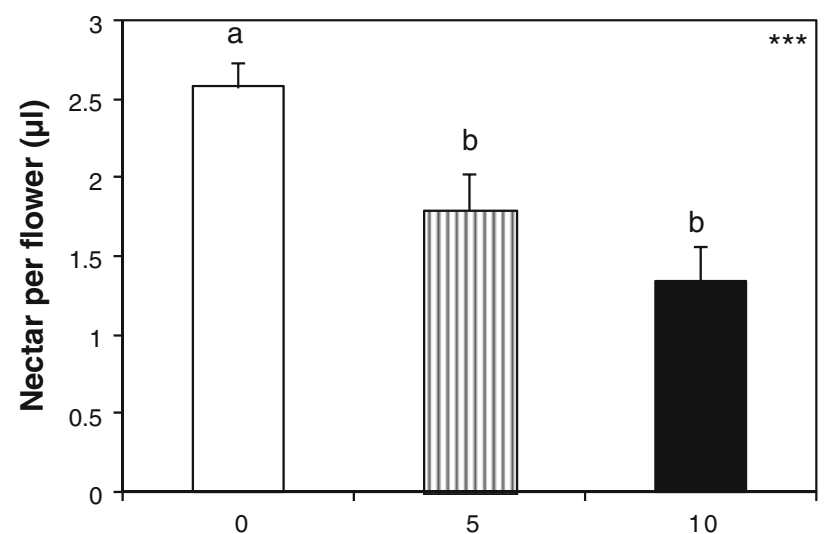

No. of $C$. infuscatus in bag

Covariates:
Temperature: NS Humidity: NS Time of day: NS

Fig. 2 Nectar volume per flower in the various infestation density treatments. Different letters indicate significant differences among treatments according to Tukey's HSD test. *** Indicates $P<0.001$ for the ANCOVA analysis. NS, not significant

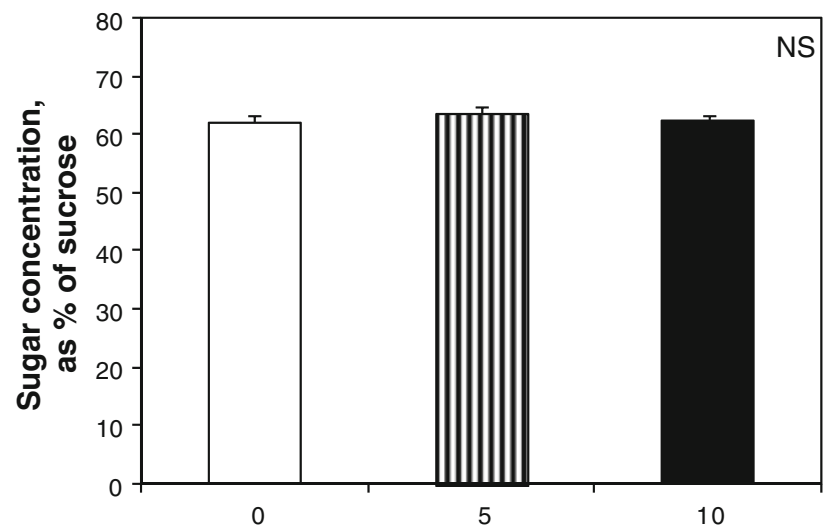

No. of $C$. infuscatus in bag

Covariates:

Temperature: NS Humidity: NS Time of day: NS

Fig. 3 Sugar concentrations (as \% sucrose equivalent) in nectar in the various infestation density treatments. $N S$, not significant

influence on reproductive success, as it can reduce the plant's attractiveness to pollinators and thereby reduce its fitness (Willson and Price 1976; Strauss et al. 1996; Lehtilä and Strauss 1997; Keasar et al. 2008).

Environmental conditions such as temperature and humidity have been regarded in the past as major factors in determining nectar yield (Corbet 1978; Bertsch 1983; Pleasants 1983). However, our present results showed no effect of these abiotic conditions, nor of the time of day, as covariates in the ANCOVA evaluation, which implies that differences in the nectar yield were indeed caused by the differences between the herbivore density treatments. The measurements were taken randomly throughout the experiment period, and therefore, we can rely on our sugar concentration data to provide a fine estimate for our nectar measurements across the herbivory density treatments. Such high values of sugar concentration in A. aestivus are not rare and have also been reported by Fahn (1948) and Lifante (1996). The finding that sugar concentrations were similar in all treatments supports the conclusion that the reductions in the amounts of nectar were due to the higher density treatment, and not to evaporation. According to Corbet (1978), the sugar concentration depended mostly on evaporation and the quantity of secreted sugar. In our present case, no sugar differences in concentration were noted. Changes in nectar volume were not due to differences in water evaporation that might have resulted from herbivory stress, but to a real effect of the herbivory on the nectary activity.

In the present study the mirid bug was never seen to feed directly from the enclosed nectar chamber. Therefore, we concluded that feeding pressure exerted by $C$. infuscatus indirectly caused a reduction in nectar volume, without the bug feeding directly on the nectar. A decrease in the amount of available resources may reduce nectar secretion, for instance, as a result of reductions in the total photosynthetic area, in the carbohydrate reserves or in nutrient stored (Mutikainen and Delph 1996). Resource availability is also a major determinant of the amount and type of plant defenses (Coley et al. 1985). Under herbivory conditions, a shift in nectar production towards chemical defense might be formed (Kessler and Baldwin 2002). In the present study, the mirid bug infection was confined to the inflorescence by means of a closed bag that contained trapped adults, while the leaves remained undamaged. Therefore, it is unlikely that any significant damage had occurred to the photosynthesis or to the stored nutrients.

One possible alternative explanation for the nectar reduction is that $C$. infuscatus feeding caused direct damage to the nectariferous tissues. Unlike many Homopterans and Psyllids, which imbibe fluid from phloem cells, most of the species from the Heteroptera order feed on parenchyma cells or xylem sap (Gullan and Cranston 2000; Schoonhoven et al. 2006). In light of the fact that nectaries are characterized by closely packed parenchyma cells (Esau 1965), it is possible that direct damage to the nectariferous tissue by $C$. infuscatus might be the cause of the decreased nectar yield.

Nevertheless, it seems that the effect of feeding from plant cells or xylem sap by this herbivore is similar to that of dehydration. Fahn (1948) examined the influence of soil moisture conditions on nectar secretion of flowers of Centaurea hyalolepis, Punica granatum and Antirrhinum majus. These plants secreted lower amounts of nectar under dehydration conditions. Furthermore, Zimmerman (1983) found that watered plants of Delphinium nelsonii produced significantly more nectar per flower than the un-watered 
controls. Other studies have also shown that water availability, in years of higher precipitation or under irrigation, increased nectar production (Wyatt et al. 1992; Petanidou et al. 1999; Keasar et al. 2008) or decreased sugar concentrations (Petanidou et al. 1995). In the present study, sugar concentration remained unchanged, whereas nectar volume decreased substantially. If lower soil moisture causes a decline in nectar amount, it is reasonable to assume that feeding from plant cells by $C$. infuscatus might have a similar effect. Moreover, drier conditions are generally reflected in lower flower production (Nicolson and Thornburg 2007). Considering that $C$. infuscatus effect on A. aestivus is similar to dehydration, it might also explain the lower number of flowers per inflorescence found in the present study.

Several aspects of the relationship between herbivory and nectar production have been studied. Some studies have pointed out a possible connection between herbivore activity and nectar production, through changes in sugar and alkaloid concentrations (Strauss 1997; Adler et al. 2006). Moreover, Krupnick et al. (1999) showed that petal feeding of Isomeris arborea by the beetle Meligethes rufimanus caused a significant decline in nectar production by a factor of up to 3 , compared with undamaged flowers. To the best of our knowledge, the present study is the first to show that insect herbivores do not necessarily have to remove segments from the flower in order to decrease nectar secretion. Such a decline in the total amount of nectar secreted due to herbivory, could be of great importance in plant fitness. It has long been established that nectar plays an important role in determining pollination frequency (Marden 1984; Keasar et al. 2008). Nectar amount and concentration can both affect pollinator response, in such a manner that can influence plant reproductive success (Whitney and Glover 2007). Several studies have also shown that flowers that offer larger quantities of nectar can receive more pollinator visits than others (Zimmerman 1983; Real and Rathcke 1991; Mitchell 1993; Hodges 1995). In the present study, some A. aestivus flowers contained no nectar at all due to the herbivore activity. This would increase variability in nectar volume reward, that might lead to risk aversion by the pollinator (Waddington et al. 1981; Hambäck 2001; Drezner-Levy and Shafir 2006). Variability in nectar reward may play a crucial role when considering plants, which unlike $A$. aestivus, do no have the capability to reproduce vegetatively. In such cases, pollination success is essential. Bees, such as bumblebees, have a foraging strategy capable of involving longer flights in case that poor flower reward patches are found (Burns and Thomson 2006). Consequently, variability in nectar amount due to herbivory can affect pollinator activity. Nevertheless, increased variability in nectar amount does not necessarily compromize pollination success. In some cases it may reduce geitonogamy, due to the pollinator avoidance from repeated visits to the same plant (Keasar et al. 2008). Therefore, such indirect effect of insect herbivore on flower nectar quantity might influence pollinators' activity in several aspects, and ultimately could affect plant reproductive success.

Acknowledgments The authors wish to thank Dan Eisikowitch for providing technical assistance and for helpful comments on this manuscript. Thanks are also extended to Sharon Gal-Or for assisting in the field work. We are grateful to Amots Dafni and Yuval Sapir for fruitful comments on this paper. The research was in part supported by the GLOWA Jordan River project and funded by the German Federal Ministry of Education and Research (BMBF), in collaboration with the Israeli Ministry of Science and Technology (MOST).

Open Access This article is distributed under the terms of the Creative Commons Attribution Noncommercial License which permits any noncommercial use, distribution, and reproduction in any medium, provided the original author(s) and source are credited.

\section{References}

Adler LS, Wink M, Distl M, Lentz AJ (2006) Leaf herbivory and nutrients increase nectar alkaloids. Ecol Lett 6:960-967

Alon A (1985) Plants and animals of the land of Israel. Insects. Ministry of defence-society for protection of nature, Israel. Vol. 3, pp. 109

Ayal Y (1994) Time-lags in insect response to plant productivity: significance for plant insect interactions in deserts. Ecol Entom 19:207-214

Ayal Y, Izhaki I (1993) The effect of the mirid bug Capsodes infuscatus on fruit production of the geophyte Asphodelus ramosus in a desert habitat. Oecologia 93:518-523

Bertsch A (1983) Nectar production of Epilobium angustifolium L at different air humidities; nectar sugar in individual flowers and the optimal foraging theory. Oecologia 59:40-48

Burns JG, Thomson JD (2006) A test of spatial memory and movement patterns of bumblebees at multiple spatial and temporal scales. Behav Ecol 17:48-55

Coley PD, Bryant JP, Chapin FS (1985) Resource availabilithy and plant antiherbivore defense. Science 230:895-899

Corbet SA (1978) Bees and the nectar of Echium vulgare. In: Richards AJ (ed) The pollination of flowers by insects. Academic Press, London, pp 21-30

Drezner-Levy T, Shafir S (2006) Parameters of variable reward distributions that affect risk sensitivity of honey bees. J Exp Biol 210:269-277

Esau K (1965) Plant anatomy, 2nd edn. John Wiley \& Sons, New York

Fahn A (1948) Nectaries of the honey plants in Israel. Hebrew Beekeeper Publishers Organization in Israel, Jerusalem 27:41-43

Fahn A (1990) Plant anatomy, 4th edn. Pergamon, Oxford, UK

Feinbrun-Dothan N, Danin A (1998) Analytical flora of Eretz-Israel, 2nd edn. Cana, Jerusalem, p 769

Gullan PJ, Cranston PS (2000) The insect—an outline of entomology. Blackwell Science, London, p 249

Hambäck PA (2001) Direct and indirect effects of herbivory: feeding by spittlebugs affects pollinator visitation rates and seed set of Rudbeckia hirta. Ecoscience 8:45-50 
Hodges SA (1995) The influence of nectar production on Hawkmoth behavior. Self-pollination and seed production in Mirabilis multiflora (Nyctaginaceae). Am J Bot 82:197-204

International Commission for Uniform Methods of Sugar Analysis (1936) International temperature correction table. Int Sugar J 3:924

Juenger T, Berelson J (1997) Pollen and resource limitation of compensation to herbivory in scarlet gilia, Ipomopsis aggregata. Ecology 78:1684-1695

Karban R, Strauss S (1993) Effects of herbivores on growth and reproduction of their perennial host, Erigeron glaucus. Ecology 74:39-46

Keasar T, Sadeh A, Shmida A (2008) Variability in nectar production and standing crop, and their relation to pollinators visit in a Mediterranean shrub. Arthropod Plant Interact 2:117-123

Kessler A, Baldwin IT (2002) Plant responses to insect herbivory: the emerging molecular analysis. Ann Rev Plant Biol 53:299-328

Krupnick GA, Weis AE (1999) The effect of floral herbivory on male and female reproductive success in Isomeris arborea. Ecology 80:135-149

Krupnick GA, Weis AE, Campbell DR (1999) The consequences of floral herbivory for pollinator service to Isomeris arborea. Ecology 80:125-134

Lehtilä K, Strauss S (1997) Leaf damage by herbivores affects attractiveness to pollinators in wild radish, Raphanus raphanistrum. Oecologia 111:396-403

Lehtilä K, Strauss S (1999) Effects of foliar herbivory on male and female reproductive traits of wild radish, Raphanus raphanistrum. Ecology 80:116-124

Lifante ZD (1996) Reproductive biology of Asphodelus aestivus (Asphodelaceae). Plant Sys Evol 200:177-191

Marden JH (1984) Intrapopulation variation in nectar secretion in Impatiens capensis. Oecologia 63:418-422

Mitchell RJ (1993) Adaptive significance of Ipomopsis aggregata nectar production observation and experiment in the field. Evolution 47:25-35

Mothershead K, Marquis JR (2000) Fitness impacts of herbivory through indirect effects on plant-pollinator interactions in Oenothera macrocarpa. Ecology 81:30-40

Mutikainen P, Delph LF (1996) Effect of herbivory on male reproductive success in plants. Oikos 75:353-358

Nicolson SW (2007) Nectar consumers. In: Nicolson SW, Nepi M, Pacini E (eds) Nectaries and nectar. Springer, The Netherlands, pp 289-342

Nicolson SW, Thornburg RW (2007) Nectar chemistry. In: Nicolson SW, Nepi M, Pacini E (eds) Nectaries and nectar. Springer, The Netherlands, pp 215-264
Pacini E, Nepi M, Vesprini JL (2003) Nectar biodiversity: a short review. Plant Sys Evol 238:7-21

Petanidou T, Van Laere AG, Smets E (1995) Changes in floral nectar components from fresh to senescent flowers of Capparis spinosa L. (Capparidaceae), a nocturnally flowering Mediterranean shrub. Plant Sys Evol 199:79-92

Petanidou T, Goethals V, Smets E (1999) The effect of nutrient and water availability on nectar secretion and nectary structure of the dominant Labiatae species of phrygana. Syst Geog Plants 68:233-244

Pleasants MJ (1983) Nectar production patterns in Ipomopsis aggregate (Polemoniaceae). Am J Bot 70:1468-1475

Quesada M, Bollman K, Stephenson AG (1995) Leaf damage decreases pollen production and hinders pollen performance in Cucurbita texana. Ecology 76:437-443

Real LA, Rathcke BJ (1991) Individual variation in nectar production and its effect on fitness in Kalmia latifolia. Ecology 72:149-155

Sawidis T, Weryszko-Chmielewska E, Anastasiou V, Bosabalidis AM (2008) The secretory glands of Asphodelus aestivus flower. Biologia 63:1118-1123

Schoonhoven LM, van Loon JJA, Dicke M (2006) Insect-plant biology. Oxford University Press, New York

Schuster A, Noy-Meir I, Heyn CC, Dafni A (1993) Pollinationdependent female reproductive success in a self-compatibile outcrosser, Asphodelus aestivus Brot. New Phytol 123:165-174

Strauss S (1997) Floral characters link herbivores, pollinators, and plant fitness. Ecology 78:1640-1645

Strauss S, Conner J, Rush S (1996) Foliar herbivory affects floral characters and plant attractiveness to pollinators: implications for male and female plant fitness. Am Nat 147:1098-1107

Waddington KD, Allen T, Heinrich B (1981) Floral preferences of bumblebees (Bombus edwardii) in relation to intermittent versus continuous rewards. Anim Behav 29:779-784

Whitney HM, Glover BJ (2007) Morphology and development of floral features recognized by pollinators. Arthropod Plant Interact 1:147-158

Willson MF, Price PW (1976) The evolution of inflorescence size in Asclepias (Asclepiadaceae). Evolution 31:495-511

Wyatt R, Broyles SB, Derda GS (1992) Environmental influences on nectar production in Milkweeds (Asclepias syriaca and A. exaltata). Am J Bot 79:636-642

Zimmerman M (1983) Plant reproduction and optimal foraging: experimental nectar manipulations in Delphinium nelsonii. Oikos 41:57-63 